Medical Education

\title{
The pre-registration year: 'service versus education' Report of a meeting organized by the National Association of Clinical Tutors held on 5 November 1992 at the Royal Society of Medicine
}

\author{
Annabelle S.J. Baughan \\ Ashford Hospital, Ashford, Middlesex TW15 3AA, UK
}

This meeting was excellent. It brought together committed medical educationalists from differing backgrounds, including clinical tutors, postgraduate deans and undergraduate deans. Dr Peter Wilkinson, Chairman of the National Association of Clinical Tutors (NACT) introduced the meeting and described the process of which we are all too aware. Every year, we take 4,000 bright, motivated and highly educated young people and within the 12 months of the pre-registration year the system appears to turn many of them into tired demotivated cynics. The educational content of much of the pre-registration house officer's (PRHO) work is minimal, the supervision often worse. The tired cliché of 'see one, do one, teach one' is highly relevant to the type of training that these doctors receive. Recognition of the very serious problems of the pre-registration year is not a new phenomenon; for example, the Association for the Study of Medical Education (ASME) report in $1983^{1}$ stated that educational objectives were not clear, consultants were unaware of their educational responsibilities, there was a lack of suitable induction into the posts, PRHOs were not formally supervised in their history taking and clinical examination skills, there were no standards available to check the acquisition of practical skills and there should be six hours a week for private study and education sessions. ${ }^{1}$ Plus ça change.

The first speaker, Professor David Shaw, Chairman of the Education Committee of the General Medical Council (GMC), considered that ... 'the pre-registration year is the worst failure of any medical education enterprise in Britain'. He hoped that this meeting would be pivotal in bringing about changes and he examined the reasons as to why the pre-registration year is not what it should be. The GMC Education Committee was statutorily responsible for determining the patterns of experience suitable for general medical training, the length of the training, the branches of medicine involved and the form of certification. In 1972 and 1980 the GMC issued codes of good practice that established that the principal purpose of the pre-

Correspondence: A.S.J. Baughan, M.R.C.P., M.R.C.Path. Received: 17 November 1992 registration period was clinical training supervised by senior staff who accepted the educational nature of the post. He conceded that the effect of the 1980 recommendations was minimal and discussed the contents of the 1987 and 1992 recommendations. The 1992 paper draws attention to what PRHOs should not be doing, for example, routine venepuncture and bed location; the University of London has issued similar recommendations ${ }^{2}$ and the University's postgraduate deans are insisting that these are followed before PRHO posts are accredited. Professor Shaw described many other initiatives to clarify and improve the experience in the pre-registration year, starting with the Goodenough report of 1944 . This made for depressing listening. There has been a run of very similar recommendations over the last 40 years but the PRHO year still remains deeply unsatisfactory.

Dr Edwin Borman, Chairman of the Junior Doctors Committee of the British Medical Association, introduced the mushroom analogy. His version, however, was somewhat restrained: 'PRHOs are classically kept in the dark and fed low-grade waste but are then expected, without further support, to blossom into well-rounded individuals.' A major challenge was to establish what is appropriate work for PRHOs, what is inappropriate work and what is appropriate work done at inappropriate times. He emphasized that we need an urgent expansion of the numbers of consultants. There are simply insufficient numbers and availability of trainers; consultants and general managers are not taking this on board. He also emphasized what we all know, but which very few managers do anything about, which is that the working environment must be improved in all professional and pastoral aspects to provide enough support for the PRHOs to withstand the stresses of their first working year. The goal of the year should be to produce competent generalists. It should complement undergraduate training and it must be used to develop clinical, communication and managerial skills (including stress management). In the context of current discussions about changing the format of the pre-registration year, perhaps extending it to 2 years, Dr Borman reported that the overwhelming view of current junior staff is that, if pre-registration training is 
worth doing at all, then it is worth doing properly and in only one year.

This was a timely comment to make. The next speaker, Professor Peter Richards, dean of St Mary's Hospital Medical School, has recently put forward suggestions that pre-registration training should be extended to a job-sharing 2 year post combined with an option of a shorter undergraduate curriculum. The advantages of such a system are that medical students become wage earners at an earlier age and that they are exposed earlier to clinical learning through clinical responsibility. However, it is clear that there are many drawbacks to this system, not least that greater supervision would be needed and much more cover will be required to allow for attendance at educational sessions. It would be more expensive and logistically more difficult. Another option was to change the final undergraduate year and insert a 3 month period of 'additional clinical practice' into the time between graduation and the beginning of the first PRHO post. During this time, the new doctor would work as 'shadow' houseman in the firm that he or she was due to join.

The whole pre-registration experience must be designed at the outset for a balance of experience and education and he emphasized the clear need for supervision of the acquisition of practical skills. He too felt that the PRHO year currently encapsulates the worse possible aspects of medical training and education, and that a potent reason for such slow improvement has been the inability of many senior staff to recognize that the PRHO function has changed radically over the last 20 years. The increase in high-technology care, the widespread use of intravenous therapy, the much greater turnover of patients, the lack of available bed space, etc. has transformed the working practice of the PRHO. He accepted that there is currently a crisis of confidence - will a change in the PRHO year merely transfer the agony to the next phase of training? There is a crisis of credulity - is there the political will and available finance to achieve change? Finally, there is a crisis of command - who will be responsible for the assessment and implementation of change? During questions to Professor Richards, the point was made that improvements in PRHO training will continue not to be achieved whilst so many different bodies appear to take some sort of responsibility for the preregistration year, set up committees to try and improve it and then work on this in discrete parallel groups. Currently, input into the PRHO debate is coming from the undergraduate deans, the postgraduate deans, the British Medical Association, the General Medical Council, regional health authorities and the Royal Colleges. Surely we need one small national body to focus on this part of medical training?
Ms Sue Barrett of the Centre for Social Management, University of Bristol, started the second session of the day with a presentation entitled 'Managing professional training in a service organization'. Such management is not an easy task as there has to be a balance in allowing PRHOs to gain skills and professional judgment weighed against the need to maintain standards of competence and risk avoidance. It is crucial that PRHOs are provided with opportunities to learn how to operate as professionals within such a complex organizational structure and the management of change in the midst of political influences on organizational life cannot be underestimated. Is the PRHO a student on placement or an employee receiving in-service training? The issues of accountability and responsibility in the relationships between the medical profession itself and medical educators are extremely complex and need to be clarified. PRHOs appear to be veering constantly between the widely differing intentions and expections of various supervisory bodies. At one end of the spectrum, the GMC feel that PRHOs are really students on placement; very much at the other end are the NHS's expectations of them as employees. She deplored the lack of an overall framework for managing the complex transition from undergrad uate to fully trained professional. For all these changes to occur, developmental work is needed in three main areas. A strategic framework must be developed for relationships between the profession; employers, educators and trainees. An operational framework needs to be introduced for day to day supervision and support to ensure that learning occurs and that their clinical practice is safe and competent. Finally, the educational process itself during this year must be properly designed and implemented. Many PRHOs do not see themselves as learners which can produce serious conflict between the concept of 'self-learning' (from practice and experience) and the concept of 'being taught'. The methodology of learning appears not to be taught at undergraduate level or during the pre-registration year; it should be. The PRHOs need to know what is required of them, they need their work overseen and they need to be given feedback on their performance. This must all happen in the context of a general support system offering advice and help and sharing responsibility for sorting priorities. Again, the importance of appropriate pastoral care was emphasized. One of the major problems is the supervision and support system. How should it be done and who should do it? Currently there are too many people providing informal support without accountability, for example, ward nursing staff. A coordinated structured framework for the pre-registration year should be developed. It will foster stability and a sense of belonging and will provide continuity for 
PRHOs and for those providing their educational and managerial support. ${ }^{3}$

Mr Ray Rowden, currently chief executive of the West Lambeth Community Trust but speaking from the perspective of the Royal College of Nursing, stated that the nursing profession is very important in the training of junior doctors. There has now been a change in nursing attitudes to professional tasks - once highly flexible, then prescriptive and rigid, now back full circle to the United Kingdom Central Council (for Nurses, Midwives and Health Visitors) (UKCC) policy that a registered nurse is a competent practitioner able to perform a wide range of clinical tasks. He emphasized that the problems of sexism and class structures have been a serious barrier to the integration of some aspects of nursing and medical education and to the solution of who does what at ward level. He was very much in favour of multidisciplinary learning and stressed the importance of facilitating communication between doctors and nurses at all times, not just at times of crisis. One of many suggestions was that junior medical teams should be ward based rather than firm based and that each unit should have a nurse/junior doctor liaison committee. He did, however, stress that any local developments in changing skill mix must have the leadership of senior nurses and consultants.

Mr Tim Matthews, chief executive at St Thomas' Hospital, looked at the role of general managers in the PRHO year and started encouragingly, many would feel accurately, with the statement 'Mea culpa on behalf of general managers. The problems of PRHOs have not been dealt with properly'. The difficult balance is to satisfy the requirements for patient care but also to work within the constraints of staffing and financial resources while maintaining educational standards. He did not see this as an insurmountable problem but merely one that needed imaginative solving. A caveat was sounded in that the more one tries to establish absolute standards in patient care, the more the trade-offs for this have to be forced back into educational standards and resources. Absolute standards in either therefore cannot be achieved; what can be reached is a working balance between the conflicting needs.

Current issues for general management are that clinicians accept their role as managers and that PRHOs and employers have clear-cut expectations of each other, including at contractual level. Structures for accountability need to be in place. For example, in their clinical work, PRHOs should perhaps be accountable to their clinical director and thus to the chief executive. For the educational content of the posts, the accountability would be to the University. He acknowledged that pastoral support of PRHOs was very poor and that general managers usually only responded to problems, for example, with accommodation, by crisis intervention. Discussion after his presentation raised the vexed point as to the role of medical staffing departments and whether or not they should be incorporated within postgraduate medical centres. The clinical tutors in the audience felt that they should be; Mr Matthews disagreed.

The final session was started by Dr Sue Dowling, Senior Lecturer in the Department of Epidemiology and Public Health Medicine at the University of Bristol, who discussed the changing boundaries between the work of doctors, nurses and support workers and the implications this had for general medical training. ${ }^{3}$ She acknowledged that highly creative solutions were needed to enable finding the balance between the service demands and the PRHOs' needs - reducing the hours of work, increasing the educational experience and enhancing their ability to lead a normal life. With the implementation of the New Deal there have been scattered initiatives in Britain but evaluation at these pilot sites was incomplete so far. What options are there? One can increase the available number of existing staff, such as phlebotomists and ECG technicians, to support the PRHO. One can also widen the range of tasks of current staff, for example, nurses and Senior House Officers (SHO). A most interesting area was in the development of new staff groupings, for example, intravenous therapy teams, nurse practitioner house officers, etc. Most importantly, we must all look closely at aspects of de-skilling and re-skilling so that the PRHO year can become a relevant training and educational experience.

A primary analogy of hospital organization was the managerial structures in the car manufacturing industry. The classical model, 'Fordism', involved tightly defined, repetitive frequent tasks. This model had needed to change because of changing technology and the changing market place - both aspects are relevant to medicine. The Fordist model creates functional divisions, excessive movements between different work areas and centralized control with top-down rules, at the expense of a horizontal coordinated approach. Work involving limited tasks provokes boredom and errors and multiskilled staff feel very threatened about being de-skilled. There are also problems with quality assurance within this model. Classically, such an organization is very inflexible, particuarly in adapting to change. However, the post-Fordist organizational model, although it might transform aspects of medical training, did have some weaknesses not least an absolute obsession with quality. The principles included a patient-led decentralized service and cross-training, for example, nurses performing limited pathology investigations. It is unclear where junior doctors would fit into the post-Fordist model and it is extremely difficult to 
create this structure at unit level because of interprofessional suspicion and rivalry. Some work has been developed in this area - the possibility of a partially joint curriculum for nurses and doctors in training, combined teaching sessions for qualified nurses and doctors and such practical aspects as the multidisciplinary use of patients' casenotes. The medical profession is facing an evolutionary crisis with the changing nature of health care, the urgent changes needed in doctors' working hours and the national, indeed pan-European, discussions on the content and length of specialist training. What we need to do is to achieve the flexibility necessary to achieve change while maintaining the core professional values that are unique to the various health professions.

Dr Peter Wilkinson then discussed aspects of education and training for PRHOs and emphasized the pivotal role of the clinical tutor in achieving local change. Change must be by consensus and not by imposition and clinical tutors need both time and training to perform the task, with very close back-up from the postgraduate deans. What topics should be included in a core curriculum for PRHOs? Important examples include common clinical emergencies, basic general management skills and structures, study and communication skills, in the context of continuing supervised training in history taking, examination, diagnostic and therapeutic skills. If PRHOs are asked what they need, they will very happily produce a teaching schedule and this has been introduced at some sites, crucially in protected time. The acquisition of practical skills might be part of a monitored experiential learning programme, such as the British Postgraduate Medical Federation/University of London log books. Such educational experience can occur in many different settings, for example, ward rounds, clinics and seminars but at present the majority of education for PRHOs appeared to centre round 'drug lunches'. He stressed the importance of teachers making full use of each educational opportunity and teaching the PRHOs in their own peer group. Who should be doing the teaching? Obviously consultants have a major role to play but they have very serious competing pressures on their time, particularly with the recently extended responsibilities in management and medical audit, and this must be recognized. The teaching role of other junior medical staff, nurses and paramedical staff is crucial but would be more functional were it to be structured and supervised.

Dr Gordon Jackson, Hon. Secretary of the NACT, discussed the induction and counselling of junior medical staff: 'PRHOs cannot begin to be educated until they are properly fed, housed and respected.' Counselling for PRHOs has many aspects, including discussion of what is expected of them, career information and feedback on performance. The induction process into a new PRHO post should be organized by the clinical tutor but performance appraisal must come from the PRHO's educational supervisor, that is, the nominated consultant on their clinical team. There is a place also for confidential 'cross' counselling, for example, of junior physicians by a senior surgeon. He described the induction process whereby new PRHOs start on 31 July. The entire day, and a hospital handbook, are organized by the outgoing house staff. The day is structured to reduce the level of anxiety in the new doctors - they are not in a position to learn anything at all until this has been addressed. ${ }^{4}$

He advocated three counselling sessions during each 6 month post with a 'how do you do?' session in which the ground rules for their work are set. This is followed 2 months later by a "how are you doing?' session. The sessions must be private and undistrubed and it must be compulsory for consultants to perform them. He suggested that no written record is kept of these sessions. Towards the end of the post, the educational supervisor and the PRHO should meet again to discuss 'how did you do?'. Disussion after his presentation brough up many salient points including the concern that a number of housemen are trained elsewhere im Europe and come to Britain with very different expectations of the year compared to British graduates. This will affect the planning of appro priate induction and counselling support. It was also important to make specific arrangements for February first-time PRHO postholders; this group because of the timing nationally of finals examinations, will almost all be initial graduation 'failures' and will therefore be even more vulnerable in their new role as PRHO.

Dr Michael Nicholls, postgraduate dean of South East Thames Region, finished the day by looking at the responsibilities of the postgraduate deans. He discussed their role in financial accountability in postgraduate education and the importance of not granting accreditation to PRHO posts that did not meet educational and pastoral standards. He described the process of post approval and alluded to the problem that serious deficiencies in a post, revealed during the dean's accreditation inspection, are very often well known to local senior staff but have never been dealt with. The role of the dean included the setting of region-wide standards for the PRHO year and the promotion of a proper educational climate, enforcing a balanced training experience. Other responsibilities of the postgraduate deans include involvement in the task force concerned with implementation of the New Deal on doctors' hours. The vexed question of SHO numbers was being discussed again; it is also important that the deans are able to influence the 
undergraduate curriculum to enable medical students to arrive better prepared for their PRHO post. It was emphasized during the discussion of this paper that satisfactory postgraduate training must be based on the content of the training programme and not on the time spent in training posts.

A summary of the day? The pre-registration year is awful. Graduates are ill-prepared for the type of tasks that they will need to perform, they are badly supervised, there is too little teaching, their working hours are excessive and their pastoral support is usually grossly inadequate. We all know this. Most of us knew it when we were PRHOs and some of us have been trying to do something about it ever since. There is no doubt whatsoever that the pre-registration experience must be improved; a meeting such as this, which brought together so many different viewpoints, must facilitate change.

\section{References}

1. Rhodes, P. The Pre-registration Year. ASME Occasional Publication 2. Association for Medical Education, Dundee, 1983.

2. University of London. Inappropriate duties for preregistration house officers. $\mathrm{Br}$ Med J 1991, 302: 568-571.
What is now desperately needed is a national group that takes heed of the views of the different professional groups concerned and is given the power to make changes. We can not afford, neither morally nor financially, to destroy the will and motivation of this very precious group of new doctors. The lack of implementation of suggested changes, some declared over 30 years ago, is a disgrace. Different interest groups must stop reinventing the wheel and work together to make the pre-registration training all that is should be.

Perhaps in a few years time, a meeting on the PRHO experience will be able to describe these doctors not as mushrooms but as orchids: 'Highly valued, appreciated by everyone, already starting to bloom before they are put into the hothouse and surrounded by responsible people who ensure that their every need is catered for.' This should not be a dream, it must be reality.

3. Dowling, S., Barrett, S. Doctors in the Making: The Experience of the Pre-registration Year. SAUS Publications, University of Bristol. 1991.

4. Gale, R., Jackson, G. \& Nicholls, M. How to run an induction meeting for house officers. $\mathrm{Br}$ Med J 1992, 304: 1619-1620. 